\title{
APLIKASI SIMULASI ALGORITMA PENJADWALAN SISTEM OPERASI
}

\author{
Raissa Amanda Putri \\ Program Studi Sistem Informasi, STMIK Mikroskil \\ Jl. Thamrin No. 140 Medan \\ raissa@mikroskil.ac.id
}

\begin{abstract}
In the operating system course, various scheduling algorithms with complex calculations are studied. The scheduling algorithms that are often used are FIFO (First-in, first out) or FCFS (first come, first serve), SJF (Shortest Job First), RR (Round robin) and SRF (Shortest remaining first). Unfortunately, the scheduling algorithm learning method often only uses the Gantt Chart as a tool for its calculations. For this reason, the researcher intends to design and build a desktop-based operating system scheduling algorithm simulation application as a learning medium for operating system courses. The application built can simulate four types of queues, namely FIFO (First-in, first out) or FCFS (first come, first serve), SJF (Shortest Job First), RR (Round robin) and SRF (Shortest remaining first). This application performs a simulation by calculating the start time, completion time, response time and waiting time for each process. In addition, the system also produces the results of the average response time and average waiting time, as well as a gantt chart of the entire process.
\end{abstract}

Keywords - Application, Simulation, Operating System, Scheduling Algorithm.

\begin{abstract}
Abstrak - Dalam mata kuliah sistem operasi, berbagai algoritma penjadwalan dengan perhitungan yang kompleks dipelajari. Algoritma penjadwalan yang sering digunakan adalah FIFO (First-in, first out) atau FCFS (first come, first serve), SJF (Shortest Job First), RR (Round robin) dan SRF (Shortest Remaining First). Sayangnya, metode pembelajaran algoritma penjadwalan seringkali hanya menggunakan Gantt Chart sebagai alat bantu perhitungannya. Untuk itu peneliti merancang dan membangun aplikasi simulasi algoritma penjadwalan sistem operasi berbasis desktop sebagai media pembelajaran mata kuliah sistem operasi. Aplikasi yang dibangun dapat mensimulasikan empat jenis antrian yaitu FIFO (First-in, first out) atau FCFS (first come, first serve), SJF (Shortest Job First), RR (Round robin) dan SRF (Shortest remaining first). Aplikasi ini melakukan simulasi dengan menghitung saat mulai, saat rampung, lama tanggap dan lama tunggu masing-masing proses. Selain itu, sistem juga mengeluarkan hasil rata-rata lama tanggap dan rata-rata waktu tunggu, serta gantt chart dari keseluruhan proses.
\end{abstract}

Kata Kunci - Aplikasi, Simulasi, Sistem Operasi, Algoritma Penjadwalan.

\section{PENDAHULUAN}

Sistem operasi adalah perangkat lunak sistem komputer yang dapat membantu perangkat keras dalam menjalankan fungsi-fungsinya termasuk manajemen proses atau kontrol proses [1]. Proses adalah keadaan ketika suatu program dijalankan. Saat komputer sedang berjalan, ada banyak proses yang berjalan serentak. Ketika suatu proses dibuat maka proses tersebut dapat memperoleh sumber daya tersebut seperti waktu $C P U$, memori, file, atau perangkat I/O[2]

Dalam penjadwalan terdapat beberapa metode yang digunakan untuk melakukan proses antrian. Beberapa algoritma yang populer antara lain FIFO (First-in, first out) atau FCFS (first come, first serve), SJF (Shortest Job First), RR (Round robin) dan SRF (Shortest remaining first). Metode pembelajaran yang dilakukan untuk mempelajari mengenai penjadwalan hanya dengan menggunakan Gantt Chart serta perhitungan Average Waiting Time (AWT) secara manual, sehingga mahasiswa akan sulit mengetahui cara kerja penjadwalan $C P U$ secara mendalam [3].

Penelitian sebelumnya telah dilakukan oleh Putra dkk dengan judul Aplikasi Simulator Algoritma Penjadwalan Central Processing Unit Menggunakan
Actionscript 3.0. Namun pada penelitian tersebut aplikasi hanya dapat mensimulasikan dua algoritma penjadwalan yaitu First-Come-First-Served dan nonpreemptive Shortest-Job-First. Selain itu, pada penelitian tersebut tidak ditampilkan gantt chart dari keseluruhan proses.

Dalam penelitian ini, dilakukan rancang bangun aplikasi simulasi algoritma penjadwalan yang meliputi materi dan simulasi masing-masing algoritma, serta pada simulasi menghasilkan rata-rata lama tanggap dan rata-rata waktu tunggu dari masingmasing algoritma tersebut. Tujuan dari rancang bangun aplikasi ini adalah sebagai alat bantu pembelajaran materi algoritma penjadwalan pada mata kuliah sistem operasi.

\section{A. $\quad$ Sistem Operasi}

Sistem operasi adalah perangkat lunak yang mengelola perangkat keras komputer. Perangkat keras harus menyediakan mekanisme yang tepat untuk memastikan pengoperasian sistem komputer yang benar dan untuk mencegah program pengguna mengganggu pengoperasian sistem yang benar [4].

Sistem operasi merupakan salah satu bagian terpenting dalam sistem komputer. Interaksi antara perangkat lunak dengan perangkat keras hanya 
dimungkinkan dengan adanya sistem operasi. Oleh karena itu, pada sistem komputer, hardware dan program-program aplikasi akan menjadi tidak berarti tanpa adanya dukungan dari sebuah sistem operasi yang handal [5].

Sistem operasi bertanggung jawab untuk mengelola sumber daya sistem komputer secara efisien dan adil. Ini termasuk prosesor $(C P U)$, memori (fisik dan virtual), perangkat seperti disk, file dan direktori, dan koneksi jaringan (port) [6].

Dari pengertian di atas dapat disimpulkan bahwa sistem operasi adalah perangkat lunak yang mengontrol perangkat keras agar lebih mudah digunakan. Sistem operasi juga dapat mengendalikan program lain dalam sebuah komputer serta sebagai pengalokasian sumber daya komputer, seperti mengatur memori, printer, dan perangkat lainnya.

\section{B. Penjadwalan}

Setiap kali $C P U$ dalam keadaan idle, sistem operasi harus memilih salah satu proses dalam antrian yang siap untuk dieksekusi. Proses seleksi dilakukan oleh short-term scheduler, atau CPU scheduler. Penjadwal memilih proses dari proses dalam memori yang siap dieksekusi dan mengalokasikan $C P U$ ke proses itu [7].

Penjadwalan $C P U$ adalah proses dimana menentukan antrian yang siap untuk dieksekusi oleh $C P U$. Penjadwalan mengatur banyaknya sumber daya agar dapat bekerja dengan lebih optimal [8].

Penjadwalan merupakan sekumpulan mekanisme sistem operasi yang berkaitan dengan urutan kerja proses yang sering dilakukan pada sebuah sistem komputer. Tujuan dari penjadwalan adalah untuk memutuskan proses mana yang harus berjalan lebih dulu, kapan, serta berapa lama waktu yang diperlukan untuk menjalankan proses-proses tersebut.

Terdapat 2 strategi penjadwalan yaitu penjadwalan preemptive dan non-preemptive. Penjadwalan preemptive yaitu proses lain dapat mengambil alih jatah waktu proses lain. Penjadwalan non-preemptive yaitu apabila suatu proses tidak dapat diambil alih oleh proses lain apabila sudah diberi jatah sampai proses tersebut selesai[4].

\section{Algoritma Penjadwalan \\ 1. $\quad$ FIFO (First In First Out)}

Algoritma penjadwalan yang paling sering digunakan, paling sederhana, non preemptive dan tidak berprioritas. Proses diberi jatah berdasarkan waktu datangnya dan dijalankan sampai proses selesai. Pada Algoritma penjadwalan $F I F O$, proses yang tiba lebih dahulu akan dilayani lebih dahulu[9].

Tabel 1. Contoh Perhitungan FIFO

\begin{tabular}{|c|c|c|c|c|c|c|}
\hline $\begin{array}{l}\text { Nama } \\
\text { Proset }\end{array}$ & $\begin{array}{l}\text { Saat } \\
\text { Tiba }\end{array}$ & $\begin{array}{l}\text { Lama } \\
\text { Proses }\end{array}$ & $\begin{array}{l}\text { Saat } \\
\text { Mulai }\end{array}$ & $\begin{array}{c}\text { Saat } \\
\text { Rampane }\end{array}$ & $\begin{array}{l}\text { Lama } \\
\text { Tangeap }\end{array}$ & $\begin{array}{l}\text { Luma } \\
\text { Tenegu }\end{array}$ \\
\hline P1 & 0 & 5 & 0 & 5 & 5 & 0 \\
\hline P2 & $T$ & 3 & 5 & $B$ & 7 & 4 \\
\hline$P 3$ & 2 & 8 & 8 & 16 & 14 & 6 \\
\hline $\mathbf{P 4}$ & 3 & 6 & 16 & 22 & 19 & 13 \\
\hline \multicolumn{5}{|c|}{ Jumlah } & 45 & 23 \\
\hline \multicolumn{5}{|c|}{ Rata-rata } & 11.25 & 5.75 \\
\hline
\end{tabular}

Tabel 2. Gantt Chart FIFO

\begin{tabular}{|l|l|l|l|l|l|l|l|l|l|l|l|l|l|l|l|l|l|}
\hline 1 & 2 & 3 & 4 & 5 & 6 & 7 & 3 & 9 & 10 & 11 & 12 & 13 & 14 & 15 & 16 & 17 & 15 \\
\hline P1 & P1 & P1 & P1 & P1 & P2 & P2 & P2 & P3 & P3 & P3 & P3 & P3 & P3 & P3 & P3 & P4 & P4 \\
\hline
\end{tabular}

\section{\begin{tabular}{|l|l|l|l|}
\hline 19 & 20 & 21 & 22 \\
\hline
\end{tabular}}

\begin{tabular}{|l|l|l|l|}
\hline P4 & P4 & P4 & P4 \\
\hline
\end{tabular}

\section{2. $\quad$ SJF (Shortest Job First)}

$S J F$ adalah algoritma penjadwalan yang jarang digunakan, tak berprioritas, non preemptive serta menggunakan asumsi waktu jalan proses yang sudah diketahui. Proses dengan waktu terpendek akan dijalankan lebih dahulu, sehingga efisiensinya tinggi dan waktu tunggunya rendah[10].

Tabel 3. Contoh Perhitungan SJF

\begin{tabular}{|c|c|c|c|c|c|c|}
\hline $\begin{array}{l}\text { Nama } \\
\text { Proses }\end{array}$ & $\begin{array}{l}\text { Saat } \\
\text { Tiba }\end{array}$ & $\begin{array}{l}\text { Lama } \\
\text { Prosen }\end{array}$ & $\begin{array}{l}\text { Saat } \\
\text { Mulai }\end{array}$ & $\begin{array}{c}\text { Saut } \\
\text { Raurpuat }\end{array}$ & $\begin{array}{l}\text { Lama } \\
\text { Tangeap }\end{array}$ & $\begin{array}{l}\text { Lama } \\
\text { Tungen }\end{array}$ \\
\hline $\mathbf{P 1}$ & $\theta$ & 5 & 0 & 5 & 5 & 0 \\
\hline $\mathbf{P} 2$ & T & 3 & 5 & 8 & 7 & 4 \\
\hline P3 & 2 & 8 & 14 & 22 & 20 & 12 \\
\hline P4 & 3 & 6 & 8 & 14 & 11 & 5 \\
\hline \multicolumn{5}{|c|}{ Jumblah } & 43 & 21 \\
\hline \multicolumn{5}{|c|}{ Rata-rata } & 10.78 & 5.25 \\
\hline
\end{tabular}

Tabel 4. Gantt Chart SJF

\begin{tabular}{|l|l|l|l|l|l|l|l|l|l|l|l|l|l|l|l|l|l|}
\hline 1 & 2 & 3 & 4 & 5 & 6 & 7 & 5 & 9 & 10 & 11 & 12 & 13 & 14 & 15 & 16 & 17 & 15 \\
\hline P1 & P1 & P1 & P1 & P1 & P2 & P2 & P2 & P4 & P4 & P4 & P4 & P4 & P4 & P3 & P3 & P3 & P3 \\
\hline
\end{tabular}

\section{\begin{tabular}{|l|l|l|l|}
\hline 19 & 20 & 21 & 22 \\
\hline & & & \\
\hline
\end{tabular}}

\begin{tabular}{|l|l|l|l|}
\hline $\mathbf{P 3}$ & $\mathbf{P 3}$ & $\mathbf{P 3}$ & $\mathbf{P 3}$ \\
\hline
\end{tabular}

\section{3. $\quad R R$ (Round robin)}

$R R$ adalah algoritma penjadwalan yang preemptive dan berlangsung tanpa prioritas. Pada algoritma penjadwalan ini, secara bergiliran berdasarkan antrian, prosesor melayani sejenak setiap proses. Secara berturut-turut, proses yang telah dilayani prosesor dan belum rampung akan kembali ke akhir antrian yang ada pada saat itu, sehingga penggiliran ini berputar seperti gelang [11].

Tabel 5. Gantt Chart RR

\begin{tabular}{|l|l|l|l|l|l|l|l|l|l|l|l|l|l|l|l|l|l|}
\hline 1 & 2 & 3 & 4 & 5 & 6 & 7 & 5 & 9 & 10 & 11 & 12 & 13 & 14 & 15 & 16 & 17 & 18 \\
\hline P1 & P1 & P1 & P2 & P2 & P2 & P3 & P3 & P3 & P4 & P4 & P5 & P5 & P5 & P1 & P1 & P1 & P2 \\
\hline
\end{tabular}

\begin{tabular}{|l|l|l|l|l|l|l|l|l|l|}
\hline 19 & 20 & 21 & 22 & 23 & 24 & 25 & 26 & 27 & 28 \\
\hline P2 & P3 & P3 & P3 & P5 & P5 & P5 & P1 & P3 & P3 \\
\hline
\end{tabular}

Tabel 6. Contoh Perhitungan $R R$

\begin{tabular}{|c|c|c|c|c|c|c|}
\hline $\begin{array}{c}\text { Nama } \\
\text { Prosen }\end{array}$ & $\begin{array}{c}\text { Saat } \\
\text { Trha }\end{array}$ & $\begin{array}{c}\text { Lama } \\
\text { Proses }\end{array}$ & $\begin{array}{c}\text { Saat } \\
\text { Mulai }\end{array}$ & $\begin{array}{c}\text { Saat } \\
\text { Rampuaz }\end{array}$ & $\begin{array}{c}\text { Lama } \\
\text { Tanggay }\end{array}$ & $\begin{array}{c}\text { Lama } \\
\text { Tungau }\end{array}$ \\
\hline P1 & 0 & 7 & 0 & 26 & 26 & 0 \\
\hline P2 & 0 & 5 & 3 & 19 & 19 & 3 \\
\hline P3 & 0 & 8 & 6 & 28 & 28 & 6 \\
\hline P4 & 0 & 2 & 9 & 11 & 11 & 9 \\
\hline P5 & 0 & 6 & 11 & 25 & 25 & 11 \\
\hline \multicolumn{7}{|c|}{ Rata-rata } \\
\hline
\end{tabular}

4. SRF (Shortest remaining first)

$S R F$ adalah algoritma penjadwalan preemptive dengan prioritas. Prioritas didasarkan pada pendeknya sisa proses. Makin pendek sisa proses makin tinggi 
prioritasnya.

\section{Tabel 7. Gantt Chart SRF}

\begin{tabular}{l|l|l|l|l|l|l|l|l|l|l|l|l|l|l|l|l|l|}
1 & 2 & 3 & 4 & 5 & 6 & 7 & 8 & 9 & 10 & 11 & 12 & 13 & 14 & 15 & 16 & 17 & 18 \\
\hline & 2 & & & &
\end{tabular} \begin{tabular}{lllllllllllllllllllllll}
\hline P1 & P2 & P2 & P2 & P1 & P1 & P1 & P1 & P4 & P4 & P4 & P4 & P4 & P4 & P3 & P3 & P3 & P3
\end{tabular}

\begin{tabular}{|l|l|l|l|}
\hline 19 & 20 & 21 & 22 \\
\hline P3 & P3 & P3 & P3 \\
\hline
\end{tabular}

Tabel 8. Contoh Perhitungan SRF

\begin{tabular}{|c|c|c|c|c|c|c|}
\hline $\begin{array}{l}\text { Nama } \\
\text { Prosen }\end{array}$ & $\begin{array}{l}\text { Sat } \\
\text { Tiba }\end{array}$ & $\begin{array}{l}\text { Lama } \\
\text { Proses }\end{array}$ & $\begin{array}{l}\text { Suat } \\
\text { Mubai }\end{array}$ & $\begin{array}{c}\text { Sat } \\
\text { Rampung }\end{array}$ & $\begin{array}{l}\text { Lama } \\
\text { Tangsap }\end{array}$ & $\begin{array}{l}\text { Lxma } \\
\text { Tungug }\end{array}$ \\
\hline P1 & 0 & 5 & 0 & 8 & 8 & 0 \\
\hline$m$ & 1 & 3 & I & 4 & 3 & 0 \\
\hline$P 3$ & 2 & 8 & 14 & 22 & 20 & 12 \\
\hline P4 & 3 & 6 & 8 & 14 & 11 & 5 \\
\hline \multicolumn{5}{|c|}{ Jumlab } & 42 & 17 \\
\hline \multicolumn{5}{|c|}{ Rata-rata } & 10.5 & 4.25 \\
\hline
\end{tabular}

II. METODE PENELITIAN

A. Model Aplikasi

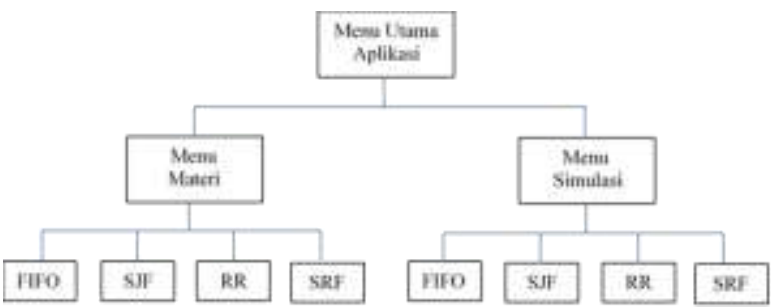

Gambar 1. Kerangka Aplikasi

Berdasarkan Gambar 1, dapat dilihat tahap-tahap dari aplikasi ini yakni sebagai berikut:

1. Pengguna membuka aplikasi simulator penjadwalan.

2. Pengguna memilih menu materi untuk mempelajari materi tentang masing-masing algoritma penjadwalan.

3. Pengguna memilih menu simulasi lalu mengisi nilai berupa jumlah proses, saat tiba dan lama proses dari masing-masing proses

4. Setelah simulasi berakhir, sistem akan memunculkan rata-rata lama tanggap, rata-rata waktu tunggu serta gantt chart.

B. Perancangan Aplikasi

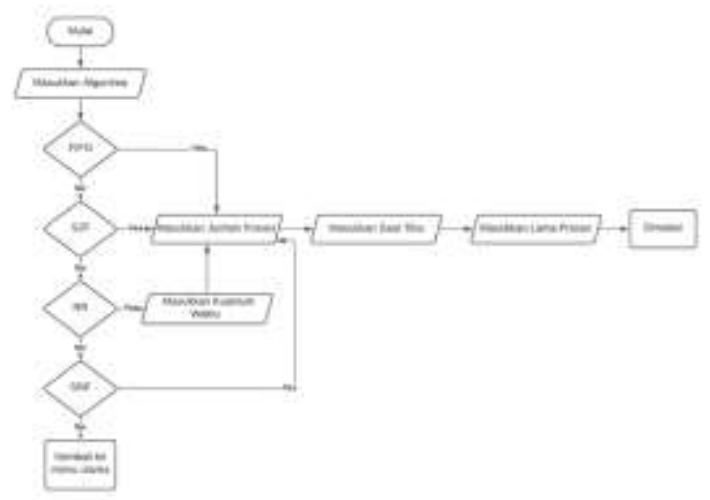

Gambar 2. Flowchart Aplikasi

Flowchart pada gambar 2 menunjukkan saat pengguna memilih menu simulasi, maka pengguna dapat memilih jenis algoritma penjadwalan yang akan disimulasi. Setelah pengguna memilih jenis algoritma, maka pengguna memasukkan jumlah proses, saat tiba dan lama proses untuk masingmasing proses. Khusus untuk algoritma penjadwalan $R R$ (Round Robin) pengguna juga harus memasukkan kuantum waktu. Setelah itu sistem akan melakukan simulasi sesuai dengan algoritma penjadwalan yang dipilih. Keluaran dari aplikasi adalah rata-rata lama tanggap dan rata-rata waktu tunggu.

\section{HASIL DAN PEMBAHASAN}

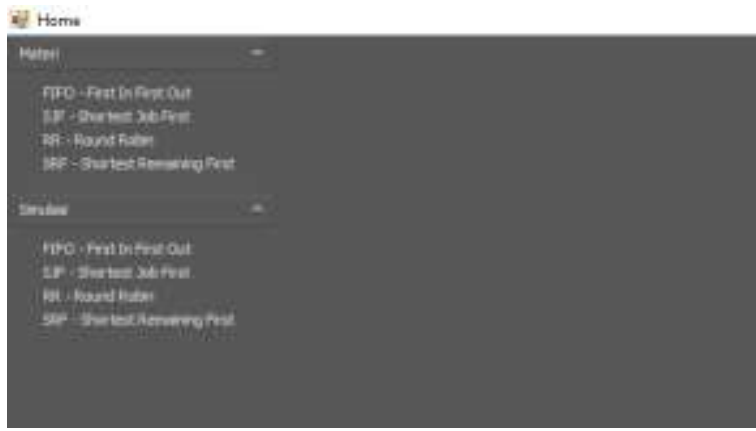

Gambar 3. Tampilan Menu Utama Aplikasi

Gambar 3 menunjukkan tampilan menu utama aplikasi yang terdiri dari 2 grup menu navigasi yaitu materi dan simulasi. Pada grup menu materi terdapat menu navigasi FIFO (First-in, first out), SJF (Shortest Job First), RR (Round robin) dan SRF (Shortest remaining first). Begitu juga pada grup menu simulasi.

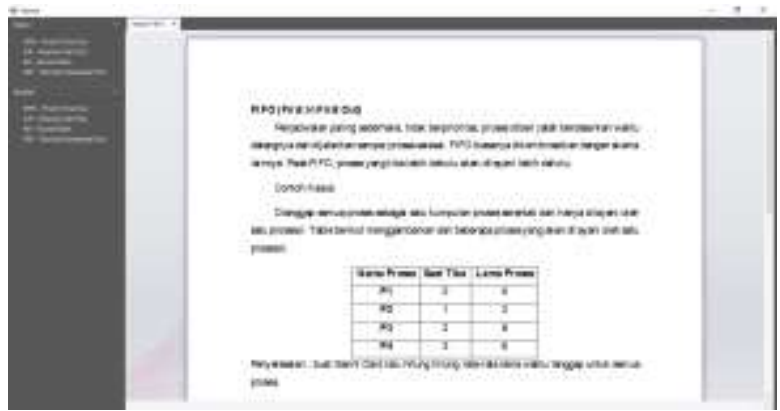

Gambar 4. Tampilan Menu Materi FIFO

Jika pengguna memilih menu FIFO (First-in, first out) yang terdapat pada grup menu materi, maka aplikasi akan memunculkan materi pembelajaran tentang algoritma penjadwalan yang dipilih.

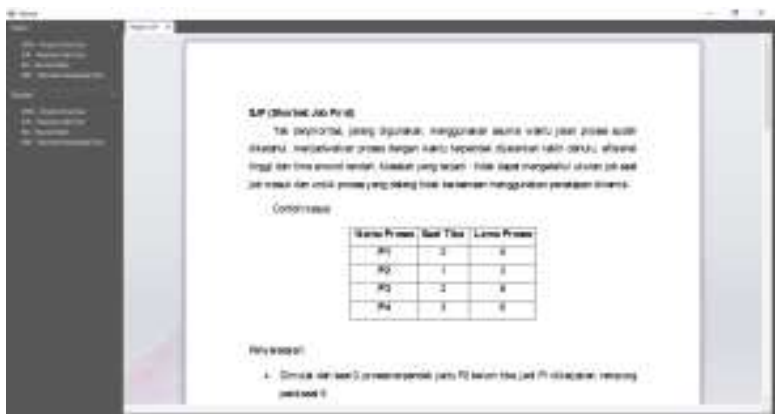

Gambar 5. Tampilan Menu Materi SJF 


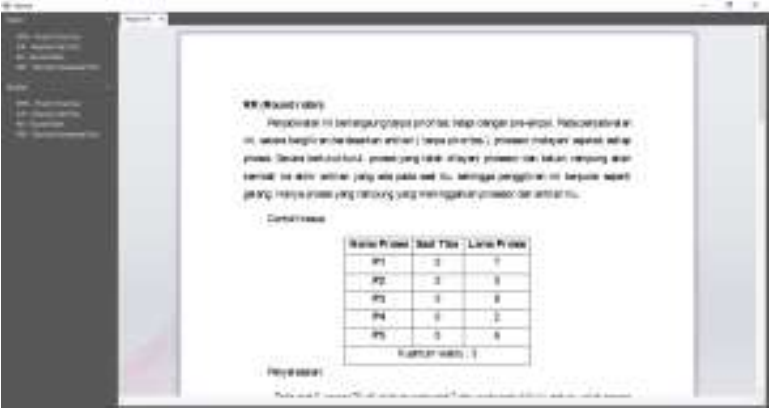

Gambar 6. Tampilan Menu Materi $R R$

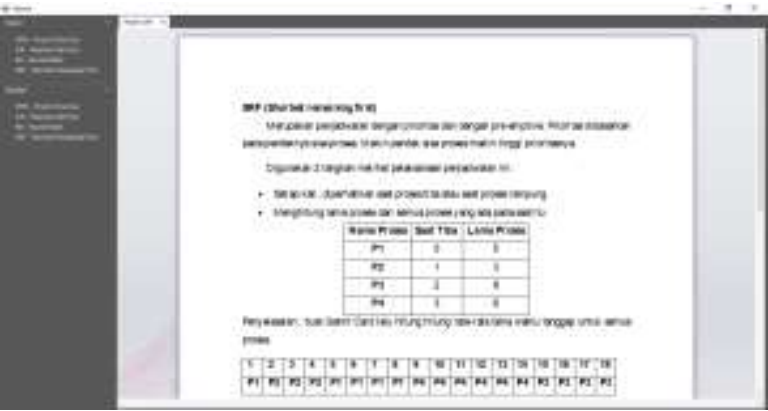

Gambar 7. Tampilan Menu Materi SRF

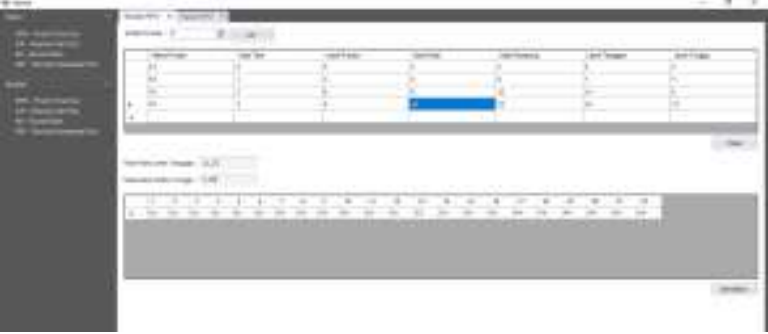

Gambar 8. Tampilan Menu Simulasi FIFO

Jika pengguna memilih menu FIFO (First-in, first out) yang terdapat pada grup menu simulasi, maka aplikasi akan memunculkan formulir simulasi algoritma penjadwalan FIFO (First-in, first out). Pengguna dapat menginput jumlah proses dengan mengetikkan angka di kolom jumlah proses, atau menekan tombol atas bawah pada NumericUpDown, lalu menekan tombol OK. Maka akan muncul baris proses sesuai dengan jumlah proses yang dimasukkan.

Selanjutnya pengguna mengisi saat tiba dan lama proses pada masing-masing baris proses lalu menekan tombol mulai, maka sistem akan mengeluarkan saat mulai, saat rampung, lama tanggap dan lama tunggu masing-masing proses. Selain itu, sistem juga mengeluarkan hasil rata-rata lama tanggap dan rata-rata waktu tunggu, serta gantt chart dari keseluruhan proses.

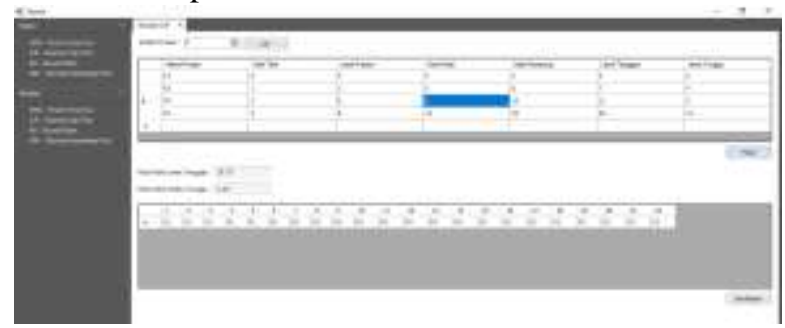

Gambar 9. Tampilan Menu Simulasi SJF

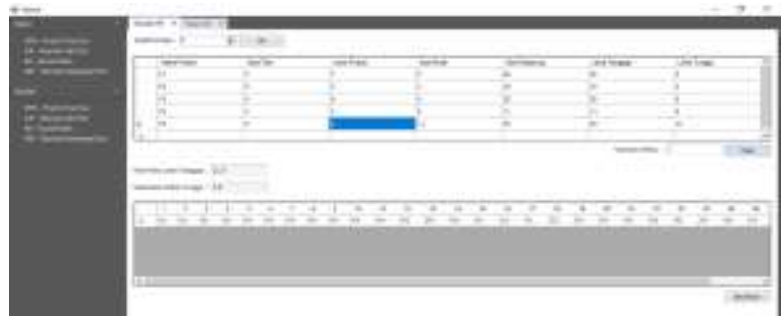

Gambar 10. Tampilan Menu Simulasi $R R$

Khusus untuk algoritma penjadwalan $R R$ (Round robin), pengguna juga harus mengimput kuantum waktu sebelum menekan tombol mulai.

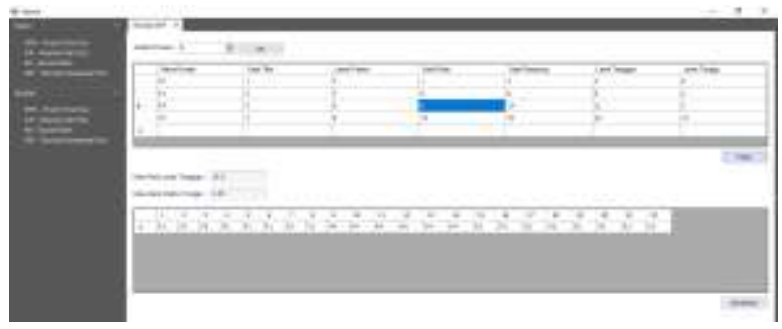

Gambar 11. Tampilan Menu Simulasi SRF

\section{KESIMPULAN}

Berdasarkan pembahasan yang dijelaskan dalam bab sebelumnya, maka didapatkan kesimpulan yaitu aplikasi yang dirancang adalah aplikasi simulasi algoritma penjadwalan sistem operasi sebagai media pembelajaran pada mata kuliah sistem operasi. Aplikasi ini dapat mensimulasikan empat jenis antrian yaitu FIFO (First-in, first out) atau FCFS (first come, first serve), SJF (Shortest Job First), RR (Round robin) dan SRF (Shortest remaining first). Aplikasi ini melakukan simulasi dengan menghitung saat mulai, saat rampung, lama tanggap dan lama tunggu masingmasing proses. Selain itu, sistem juga mengeluarkan hasil rata-rata lama tanggap dan rata-rata waktu tunggu, serta gantt chart dari keseluruhan proses.

\section{DAFTAR PUSTAKA}

[1] I. Binanto, Sistem Operasi. Yogyakarta: Andi Offset, 2005.

[2] A. P. U. Siahaan, "Comparison Analysis of CPU Scheduling FCFS, SJF and Round Robin," vol. 4, no. 3, pp. 124-131, 2017.

[3] E. Y. Putra, G. A. Sandag, and E. S. Djimesha, "Aplikasi Simulator Algoritma Penjadwalan Central Processing Unit Menggunakan Actionscript 3.0," CSRID (Computer Sci. Res. Its Dev. Journal), vol. 10, no. 3, p. 139, 2021.

[4] A. Silberschatz, P. B. Galvin, and G. Gagne, Operating System Concepts. United States of America: John Wiley \& Sons, Inc., 2013.

[5] S. Kusumadewi, Sistem Operasi. Yogyakarta: Graha Ilmu, 2002.

[6] M. Kifer and S. A. Smolka, Introduction to Operating System Design and Implementation. 
London: Springer, 2007.

[7] P. Brucker, Scheduling Algorithms. New York: Springer, 2007.

[8] M. L. Pinedo, Scheduling: Theory, algorithms, and systems, fifth edition. 2016.

[9] R. H and A. C, Operating System Three Easy Pieces. Arpaci-Dusseau Books, 2019.

[10] P. Singh, V. Singh, and A. Pandey, "Analysis and Comparison of CPU Scheduling Algorithms," Int. J. Emerg. Technol. Adv. Eng., vol. 4, no. 1, pp. 91-95, 2014.

[11] A. Noon, A. Kalakech, and S. Kadry, "A New Round Robin Based Scheduling Algorithm for Operating Systems: Dynamic Quantum Using the Mean Average," IJCSI Int. J. Comput. Sci. Issues, vol. 8, no. 3, pp. 224-229, 2011. 